\title{
Sikanjalo district hospital Procedural medicine teaching unit
}

The procedure unit is a stand-alone unit next to casualty and provides a service to all the wards and casualty as well as acting as a teaching unit.

It is designed to handle and teach office procedures and minor surgical procedures under local and regional anaesthesia (upper and lower limb and specialised anaesthetic blocks).

The unit operates daily from 08:00 to 17:00 hours. The last booking is at 16:00 hours.

The unit consists of 5 procedure areas/beds which are allocated to:

1. BOOKED MINOR SURGICAL CASES/PROCEDURES/ INVESTIGATIVE PROCEDURES, such as skin cysts, keloids, lipomas, lymph node biopsy, skin biopsy, tendon injection, joint aspiration, ganglions, warts, cryotherapy, toe nail surgery as well as lumbar punctures, pleural tap and biopsy, pericardial tap, ascites drainage, hydrocoele drainage, liver biopsy and haemorrhoid ligation.

2. SEPTIC CASES, such as abscesses, debridement of wounds and infected amputations.

3 and 4. EMERGENCY TRAUMA SURGERY, such as suturing lacerations, traumatic hand and foot surgery, chest drains, removal of foreign bodies, epistaxis and urinary or suprapubic catheterisation.

5. SPECIAL LISTS: Endoscopy list, circumcision/vasectomy list and eye surgery list.

The unit is equipped with appropriate instrument trays, autoclaves and resuscitation equipment.

FAMILY MEDICINE ROTATION: This is a one-month optional module for interns or community service doctors and preference is given to those who are considering careers in rural/semi-rural practice.
AUDIOVISUAL UNIT contains screens and projectors for teaching and a library of videos/DVDs on procedures and anatomical maps, as well as instructions for regional anaesthesia. We have televised all procedures and the videos/DVDs of these procedures as well as step-by-step visual demonstrations of regional anaesthetic blocks can be downloaded free from our website.

Teaching includes taking consent, ethical issues and quality assurance reviews.

Certain procedures are in research trials.

STAFF: 2 family physicians/lecturers, 1 professional nurse, 5 staff nurses, 1 data capture/file clerk, 1 research assistant, 1 receptionist, 1 general orderly.

Phone extension 295 for bookings, or you may book online from peripheral clinics.

Please phone our receptionist for bookings from the wards. Casualty officers should please phone through cases which will be taken depending on workloads and schedules.

The unit is structured to be a service to the hospital and surrounding clinics. CPD teaching days in office procedures are provided regularly for medical officers from surrounding hospitals and for local general practitioners. These instruction sessions can also be accessed via our telemedicine unit to surrounding and rural hospitals.

Thank you for your cooperation.

Chris Ellis is a family physician in Pietermaritzburg, KwaZulu-Natal

E mail: cristobalellis@gmail.com 